\title{
Locuras que no lo parecen
}

La preocupación por delimitar las fronteras de la locura viene de antiguo, aunque sólo con el nacimiento de la Psiquiatría se convirtió en una exigencia que la nueva ciencia debía asumir y resolver con urgencia. Como consecuencia de la consolidación de la ideología de las enfermedades mentales a lo largo del siglo XIX, se produjo una hipertrofia de la nosografía psiquiátrica que daba cuenta de las dificultades de trazar las lindes divisorias entre las diversas enfermedades mentales, y entre éstas y la normalidad. Especialmente con la aparición de las sucesivas ediciones de Psychiatrie, del profesor Emil Kraepelin, ese panorama arborescente y alambicado logró adquirir unas formas más compactas y presumiblemente definitivas. Sin embargo, también su nosografía sistemática dejaba sin resolver el problema de las formas atenuadas, rudimentarias y parciales de la locura. Al no amoldarse éstas a los presupuestos nosológicos -sea en materia etiológica, sea respecto a la sintomatología, las formas de evolución y de terminación- esas variantes de la locura fueron relegadas a posiciones marginales, suscitándose numerosas controversias al tratar de considerarlas enfermedades de pleno derecho y también cuando se pretendía determinar qué signos morbosos permitían incluirlas en algunas de las grandes categorías nosográficas descritas.

\section{Fronteras}

$\mathrm{Al}$ investigar la historia de la clínica mental atendiendo en especial a las fronteras de la locura, se observan algunos cuadros y casos clínicos que parecen rebelarse a ser incluidos entre las psicosis prototípicas, es decir, la esquizofrenia, la paranoia y la psicosis maníaco-depresiva. Tales son, entre otros, algunos de los casos descritos por Pinel y Esquirol entre los delirios parciales, las locuras razonantes, la «locura parcial» (partielle Verrücktheit) de los autores alemanes, la forma simple y la latente de la esquizofrenia bleuleriana, y, de manera especial, la locura lúcida de Trélat.

En lugar de profundizar en la especialidad de este tipo de formas clínicas, asumiendo por ello el riesgo de desbaratar los modelos psicopatológicos imperantes, la mayoría de los tratadistas se repartieron en dos posiciones contrarias: mientras unos las negaron sin más -es lo que hizo J.-P. Falret con las monomanías-, otros las incluyeron directamente en alguna de las grandes categorías existentes, como propuso Bleuler respecto a la forma simple y la latente de la esquizofrenia. Mas la simple negación ni remedia el problema ni lo aplaza, como pudo comprobarse a finales del siglo XIX con los inagotables debates acerca de la paranoia. Tampoco la solución aquí ilustrada con Bleuler está exenta de complicaciones, de 
las que con acierto se hicieron eco Ey y Guiraud al escribir: «Nuestro temor es que las mentes demasiado prudentes o demasiado hábiles, en presencia de casos dudosos [...], se refugien en la esquizofrenia, como ocurría en otro tiempo con la degeneración» 1 .

Pese a su dificultad, más atinado parece investigar esas variantes excepcionales no sólo desde los modelos tradicionales sino también a partir de otros, quizás construidos ad hoc, que permitan captar su esencia y singularidad, además de mostrar el denominador común que comparten con el resto de psicosis.

\section{Locos lúcidos}

Han sido pocas, en verdad, las monografías dedicadas por los clásicos a los locos normalizados, es decir, esos cuya vida discurre por las sendas más transitadas y caminan con un paso similar al de la mayoría de sus coetáneos. Seguramente la más ambiciosa y directa es la que publicara en 1861 Ulysse Trélat (1795-1879) con el título La folie lucide étudiée au point de vue de la famille et de la société. Médico de la Salpêtrière y más tarde de Charenton, Trélat compaginó el alienismo con un activismo político de extrema izquierda ${ }^{2}$. Partidario de la herencia como causa última de la locura, dedicó su primera obra a recuperar las opiniones de los principales médicos que se ocuparon de la locura a lo largo de la historia ${ }^{3}$. Aunando sus ideales sociales y la práctica médica, Trélat investigó durante años la folie lucide. Lo hizo con el fin de que sus colegas reconocieran a esos locos que pasan desapercibidos y pudieran salvaguardar el matrimonio, la familia y la sociedad de sus desmanes y maldades. Se trata por tanto de un tipo de alienados que, a diferencia de la mayoría, no parecen en absoluto locos cuando se les observa superficialmente. Sólo si se logra penetrar en ellos mediante un análisis de su vida íntima, se podrá apreciar la alienación que los subyuga: «Estos enfermos deliran en sus actos, pero no deliran en sus palabras. Su falta de razón sólo se conoce desde el interior y no se muestra afuera $»^{4}$. Advierte además Trélat que en los interrogatorios hacen gala de un gran dominio de sí mismos («no dan un paso en falso»), razón por la cual el médico debe atender sobre todo a los antecedentes.

1 Ey, H.; Guiraud, P., «Remarques critiques sur la schizophrénie de Bleuler» [1926], en H. Ey, Schizophrénie. Études cliniques et psychopathologiques, Condé-sur-Noireau, Synthelabo (Les empêcheurs de penser en rond), 1996, p. 30.

2 Sobre la vida y obra de Trélat, véase R. SEMELAIGNe, Les pionniers de la psychiatrie française avant et après Pinel, París, Baillière, 1930, pp. 202- 211.

3 Cf. U. TRÉLAT, Recherches historiques sur la folie, París, Baillière, 1839.

${ }_{4}$ Trélat, U., La folie lucide étudiée au point de vue de la famille et de la société, París, A. Delahaye, 1861, p. 12 . 
HISTORIA DE LA PSIQUIATRÍA

Como quiera que la inmensa mayoría son incurables, es del todo recomendable que «[...] los que están dotados de razón los conozcan para no ligarse en absoluto ni entrar en relación con ellos» 5 .

Los locos lúcidos pueden pertenecer a las diferentes categorías de la locura: imbéciles, idiotas, sátiros, erotómanos, celosos, orgullosos, etc. Pese a sus numerosas diferencias, todos ellos dan muestras de una suprema ingratitud y de una indestructible confianza en sí mismos. Estas son las dos características más destacadas que se desprenden de la monografía de Trélat, cuyos escasos resultados psicopatológicos contrastan con los elevados ideales sociales a los que está destinada.

\section{Escenarios actuales}

Durante los últimos años, esta problemática de las locuras que no lo parecen se ha reactualizado en escenarios de la clínica mental muy distantes entre sí. Con una intención clara de ampliar el número de consumidores de neurolépticos y otros psicofármacos, la industria farmacéutica trata de abrir una brecha entre aquellos jóvenes un tanto raros a los que se presume candidatos a la psicosis. De la mano de tan magnánima propuesta se ponen en marcha intervenciones precoces, esto es, el uso próspero de medicamentos para prevenir posibles locuras del futuro. Esta es una de las modalidades por las que el territorio de la psicosis se ensancha en nuestros días para acoger a supuestos esquizofrénicos o bipolares.

En las antípodas de esta orientación, tratando de conjugar la investigación psicopatológica de las formas actuales de presentación de la psicosis con una terapéutica más acorde a los tiempos, la orientación lacaniana ha promovido la noción de «psicosis ordinarias $»^{6}$, motivando un creciente número de publicaciones por el momento un tanto heterogéneas. En ellas se abren de nuevo las preguntas sobre los límites, las fronteras o los litorales que separan la locura de la normalidad, la psicosis de la neurosis. Como es natural, las propuestas que de aquí deriven deben ser suficientemente cuidadosas y no generalizar el diagnóstico de psicosis; eso traería graves perjuicios a los pacientes y arruinaría la concepción tradicional de las neurosis?

\section{José María Álvarez y Juan de la Peña Esbrí}

Trélat, U., La folie lucide, p. 16.

Cf. J.-A. Miller, y otros, La psicosis ordinaria, Buenos Aires, Paidós, 2004.

No conviene en modo alguno dejarse llevar por el entusiasmo. El propio E. Laurent reconoce que «entre las neurosis clásicas por un lado y las psicosis extraordinarias por el otro, se encuentran fenómenos mezclados, mixtos, que no son fácilmente asignables. Hay un campo de exploración clínica que justamente debe ser cualitativamente explorado. Pero, neurosis y psicosis deben ser distinguidas como dos polos completamente fundamentales» (LAURENT, E., «La psicosis ordinaria», en Virtualia, n. ${ }^{\circ}$ 16, Febrero-Marzo, 2007; www.eol.org.ar/ Virtualia). 